\title{
POLÍTICAS PÚBLICAS Y SU INFLUENCIA EN EL RECONOCIMIENTO Y EJERCICIO DE UNA CIUDADANÍA PLENA E INTERCULTURAL AL PUEBLO MAPUCHE EN CHILE
}

Nancy Yánez Fuenzalida 


\section{NANCY YÁÑEZ FUENZALIDA}

Es abogada de la Universidad de Chile y Magíster en Derecho Internacional de los Derechos Humanos de la University of Notre Dame. Además es Doctora en Derecho por la Universidad de Chile y académica de la Facultad de Derecho de la misma Casa de Estudios. 


\section{POLÍTICAS PÚBLICAS Y SU INFLUENCIA EN EL RECONOCIMIENTO Y EJERCICIO DE UNA CIUDADANÍA PLENA E INTERCULTURAL AL PUEBLO MAPUCHE EN CHILE}

\section{INTRODUCCIÓN}

El presente artículo busca analizar la política pública impulsada por el Estado de Chile a partir de la entrada en vigencia de la ley 19.253 sobre Fomento y Desarrollo de los Indígenas, y está focalizado en la situación particular del pueblo mapuche y referido a la región de La Araucanía. El análisis pone énfasis en el periodo 2009 2017, tomando como referencia que en el año 2009 entró en vigencia el Convenio 169 sobre Pueblos Indígenas y Tribales en Países Independientes, en adelante el Convenio 169. El objetivo de este artículo es determinar de qué modo estas políticas permiten garantizar el ejercicio de una ciudadanía plena e intercultural al pueblo mapuche y sus miembros en Chile.

Focalizaremos nuestro análisis en tres aspectos fundamentales: uno, situación socio-económica del pueblo mapuche y sus miembros; dos, niveles de reconocimiento de sus derechos colectivos, en particular del derecho fundamental al territorio, la tierra y los recursos naturales; y tres, acciones represivas y de criminalización del pueblo mapuche y sus miembros.

El análisis de la situación socio-económica de los mapuche busca determinar si los indicadores socio-económicos que caracterizan a la población mapuche evidencian brechas respecto de otros sectores de la población chilena, de modo que podamos constatar si existen condiciones socio-económicas discriminatorias para los mapuche en Chile y si bajo estas condiciones se puede ejercer una ciudadanía plena.

Por otra parte, el análisis de la política de tierras tiene por objetivo establecer los niveles de reconocimiento de los derechos territoriales otorgados a los pueblos indígenas en los instrumentos internacionales de derechos humanos, en particular en el Convenio 169, la Declaración de Naciones Unidas sobre los Derechos de los Pueblos Indígenas (DNUDPI) y la Jurisprudencia del Sistema Interamericano de Derechos Humanos. Cabe considerar que el derecho a la tierra, en su amplia dimensión que incluye territorio, tierra y recursos naturales, es la piedra angular del decálogo de derechos de los pueblos indígenas y que también ha sido reconocido en la legislación chilena por medio de la ley 19.253 sobre Protección, Fomento 
y Desarrollo de los Indígenas. Este enfoque se sustenta en la premisa de que el reconocimiento de los territorios ancestrales indígenas garantiza la identidad de los pueblos originarios, vinculada indisolublemente a dichos espacios y al hábitat que la configura; y al mismo tiempo viabiliza los modos de vida indígenas y sus propuestas de desarrollo conforme a sus propias perspectivas.

Finalmente, nos referiremos a las políticas represivas y de criminalización por medio de las cuales el Estado de Chile, en distintos periodos de la historia contemporánea, ha dado respuesta a las acciones de movilización y protesta social que ha impulsado el pueblo mapuche para la reivindicación de sus derechos territoriales, las mismas que la institucionalidad ha intentado desarticular.

\section{SITUACIÓN DEMOGRÁFICA Y SOCIO-ECONÓMICA DE LOS MAPUCHE EN CHILE CON REFERENCIA A LA ARAUCANÍA}

Según la Encuesta de Caracterización Socio Económica (Casen) ${ }^{1}$ del Ministerio de Desarrollo Social, en adelante encuesta Casen, correspondiente al año 2015, la población indígena auto reconocida por la vía del parentesco o apellido indígena ha incrementado de modo importante. Se pasó de 1.060 .786 personas indígenas en 2006 a 1.585.680 personas indígenas en 2015. Esta última cifra representa el $9 \%$ de la población total del país y corresponde a un aumento de más del 50\% de la población en menos de diez años, siguiendo con ello la tendencia de América Latina, según consta en el Informe Cepal $2014^{2}$.

El pueblo mapuche representa el $83,8 \%$ de la población indígena del país y está integrado por 1.329 .450 personas. El peso porcentual del pueblo mapuche respecto de los otros pueblos indígenas mantiene la tendencia del Censo de 2002, donde la población mapuche representaba el $84 \%{ }^{3}$.

1. [en línea] http://observatorio.ministeriodesarrollosocial.gob.cl/casen-Multidimensional/ casen/docs/CASEN_2015_Resultados_pueblos_indigenas.pdf. Consultada el 27 de enero de 2018.

2. Comisión Económica para América Latina (Cepal), 2014. Los pueblos indígenas en América Latina, avances en el último decenio y retos pendientes para la garantía de sus derechos, Santiago de Chile, 2014. [en línea] http://repositorio.cepal.org/bitstream/handle/11362/37222/ S1420521_es.pdf. Consultada el 27 de enero de 2018. Según dicho informe la población indígena creció en América Latina un 49,3\% entre los años 2000 y 2010 y está conformada por 826 pueblos, integrados por 45 millones de personas que representan el 8,3\% de la población mundial.

3. [en línea] http://www.ine.cl/docs/default-source/FAQ/s\%C3\%ADntesis-de-resultadoscenso-2002.pdf?sfvrsn=2. Consultada el 28 de enero de 2017. 
Un fenómeno interesante en la última década es el aumento de la tasa de migración mapuche hacia la región Metropolitana. En la región de La Araucanía, donde se ha concentrado la mayoría de la población mapuche en los siglos XX y XXI, la población indígena disminuye sistemáticamente. En el año 2009 la población indígena en la región ascendía al 24,6\% del total de población del país, mientras que en el año 2015 disminuyó al 19,6\%, según la encuesta Casen 2015. En la región Metropolitana, el aumento registrado de la población indígena coincide con la cifra en que esta ha descendido en La Araucanía, de lo que deducimos que hay un flujo de migración mapuche hacia la capital. Así lo revelan las cifras de la encuesta que venimos analizando, que registra un porcentaje de población indígena habitando en la región Metropolitana que asciende a 24,0\% para el año 2009 y 30,1 \% en el año 2015, cifras referidas al total de la población indígena del país.

No obstante el aumento sostenido de la población indígena en el país, las brechas de inserción social se mantienen, de lo que da cabal cuenta la encuesta Casen 2015. Los pueblos indígenas siguen siendo los más pobres del país. La pobreza por ingreso y multidimensional ubica a los pueblos indígenas muy por debajo de la población no indígena. La región de La Araucanía presenta el mayor porcentaje de personas en situación de pobreza por ingreso, 23,6\%, y la situación de pobreza multidimensional, que identifica carencias en diversos ámbitos como salud, educación y nivel de vida, se remonta al 26,2\%.

\section{Tabla No1}

Pobreza y pobreza extrema por ingresos y multidimensional por pertenencia a pueblos indígenas, 2015

\begin{tabular}{l|l|l|l|l|l} 
Sujetos & $\begin{array}{l}\text { Pobreza } \\
\text { por ingreso }\end{array}$ & $\begin{array}{l}\text { Pobreza } \\
\text { multidimensional }\end{array}$ & $\begin{array}{l}\text { Pobreza } \\
\text { extrema } \\
\text { por ingreso }\end{array}$ & $\begin{array}{l}\text { Hogares en } \\
\text { situación } \\
\text { de pobreza } \\
\text { por ingreso }\end{array}$ & $\begin{array}{l}\text { Hogares en } \\
\text { situación } \\
\text { de pobreza } \\
\text { multidimensional }\end{array}$ \\
\hline Indígenas & $18,3 \%$ & $30,8 \%$ & $6,6 \%$ & $16,4 \%$ & $26,4 \%$ \\
\hline $\begin{array}{l}\text { No } \\
\text { indígenas }\end{array}$ & $11,0 \%$ & $19,9 \%$ & $3,2 \%$ & $9,9 \%$ & $15,8 \%$ \\
\hline
\end{tabular}

Fuente: encuesta Casen 2015

En materia laboral no se observan grandes desigualdades en el ámbito de empleo y desempleo, salvo en el caso de las mujeres indígenas, que presentan una mayor tasa de desocupación laboral, con un 10,0\%, respecto a las mujeres no indígenas, que tienen una tasa de desocupación de 8,2\% (Casen, 2015). En La Araucanía, sin embargo, la cesantía sigue siendo la más alta del país y es así como en el 2017 
alcanzó a un 8,39\% de la población, experimentando una baja al final del año, según cifras del Instituto Nacional de Estadísticas (INE). Otras informaciones del mismo organismo indican que la región de La Araucanía supera en 2,4 puntos porcentuales la media de cesantía nacional, que asciende a $6,6 \%$, lo que la posiciona como la región con más cesantes en el periodo medido ${ }^{4}$.

La brecha, sin embargo, es extremadamente relevante en el nivel de ingreso, lo que evidencia un claro sesgo de discriminación hacia la población indígena. Las diferencias de ingreso entre la población indígena y no indígena se han mantenido entre el 2009 y el 2015 y se han incrementado, según podemos establecer en la tabla que exponemos a continuación.

\section{Tabla $\mathrm{N}^{\circ} 2$}

Niveles de ingreso población indígena y no indígena (2009 - 2015)

\begin{tabular}{l|l|l|l|l} 
Sujeto & $\mathbf{2 0 0 9}$ & $\mathbf{2 0 1 1}$ & $\mathbf{2 0 1 3}$ & $\mathbf{2 0 1 5}$ \\
\hline Indígena & 240.422 & 252.863 & 332.408 & 372.073 \\
\hline $\begin{array}{l}\text { No } \\
\text { indígena }\end{array}$ & 388.244 & 409.276 & 498.788 & 551.321 \\
\hline
\end{tabular}

Fuente: encuesta Casen 2015

Las cifras analizadas en este documento son contundentes. No cabe duda de que los miembros de los pueblos indígenas, y en particular los mapuche, viven condiciones discriminatorias que los posicionan como el grupo más vulnerable de la sociedad chilena. Bajo estas condiciones de marginación económica y social cabe poner en cuestión si los mapuche son en la práctica miembros plenos de la comunidad política, toda vez que su carta de ciudadanía ni siquiera les permite vivir en condiciones mínimas de igualdad y no discriminación respecto del resto de la población y es evidente que la política pública no ha logrado revertir esta situación. En un escenario tan desventajoso quedan proscritas las aspiraciones indígenas a ejercer una ciudadanía diferenciada por su especificidad étnica y hace ilusorio el ejercicio de su derecho inalienable a la autodeterminación como miembros de una nación preexistente al Estado de Chile .

4. [en línea] http://www.biobiochile.cl/noticias/nacional/chile/2017/04/29/region-de-laaraucania-registra-la-tasa-de-desocupacion-mas-alta-del-pais.shtml Consultada el 27 de enero de 2018.

5. Sobre el derecho a la libre determinación véase: Anaya, 2005; Mariman, 2012. 


\section{POLÍTICA DE TIERRAS INDÍGENAS Y SU INCIDENCIA RESPECTO AL PUEBLO MAPUCHE EN LA ARAUCANÍA}

En lo que refiere a derechos territoriales y siguiendo la perspectiva de la autodeterminación referida en los párrafos precedentes, no hay en Chile un reconocimiento de la propiedad ancestral de las tierras indígenas que permita la restitución del territorio ancestral y, consecuencialmente, faculte a los pueblos indígenas para ejercer una gobernanza efectiva sobre los recursos naturales y el territorio.

La política de tierras indígenas chilena se sustenta en el marco normativo que provee la ley 19.253, que dispone lo siguiente:

Reconoce que para las denominadas "etnias" indígenas, la tierra es el fundamento principal de su existencia y cultura. Establece como uno de los deberes del Estado y la sociedad en general protegerlas, velar por su adecuada explotación, su equilibrio ecológico y propender a su ampliación (artículo 1).

Identifica las tierras indígenas, incorporando en esta categoría aquellas que las personas o comunidades indígenas ocupan, sea en propiedad o posesión, y que provienen de toda clase de títulos emanados del Estado. Considera a futuro aquellas que sean declaradas por los tribunales como pertenecientes a indígenas y las que los indígenas y sus comunidades reciban a futuro a título gratuito del Estado. También identifica como tierras indígenas (ancestrales) las que históricamente han ocupado y poseen personas o comunidades indígenas, caso en que se requiere para que sean consideradas como tales que se inscriban en el registro de tierras de la Corporación Nacional de Desarrollo Indígena (Conadi) a solicitud de las respectivas comunidades o indígenas titulares de la propiedad (artículo 12) ${ }^{7}$.

Otorga protección jurídica a dichas tierras indígenas, de propiedad individual o colectiva, al disponer que estarán exentas del pago de contribuciones. La ley establece además que, "por exigirlo el interés nacional", las tierras indígenas no podrán ser enajenadas, embargadas, gravadas ni adquiridas por prescripción, salvo entre

6. Nomenclatura utilizada por la Ley Indígena que no se ajusta a los estándares internacionales, donde se denomina a los pueblos indígenas como pueblo y por tanto como sujeto político del derecho de libre determinación. Sobre el derecho de los pueblos indígenas a la libre determinación.

7. Así, el artículo $12 \mathrm{~N}^{\circ} 2$ dispone que son tierras indígenas: "Aquellas que históricamente han ocupado y poseen las personas o comunidades mapuches, aymaras, rapa nui o pascuenses, atacameñas, quechuas, collas, kawashkar y yámana, siempre que sus derechos sean inscritos en el Registro de Tierras Indígenas que crea esta ley, a solicitud de las respectivas comunidades o indígenas titulares de la propiedad". 
comunidades o personas de una misma etnia. Dispone que tampoco podrán ser arrendadas en el caso de las tierras de comunidades y sólo podrán ser arrendadas por un plazo no superior a cinco años en el caso de las tierras de propiedad individual (artículo 13).

Establece, además, que sólo podrán permutarse por tierras de no indígenas de similar valor con la autorización de la Conadi y que estas pasarán a considerarse tierras indígenas. La Conadi abriría un registro de tierras en el que se inscribirían las tierras indígenas de que trata el artículo 12 (artículo 15). En cuanto a la división de las tierras comunitarias provenientes de títulos de merced, la ley establece que se requerirá de solicitud formal al juez competente de la mayoría absoluta de los titulares de derechos hereditarios en ella (artículo 16) y que las tierras resultantes de la división de comunidades serían indivisibles, aun en el caso de sucesión por causa de muerte (artículo 17).

Establece como mecanismo para proveer la ampliación de las tierras indígenas el Fondo de Tierras y Aguas. En lo sustancial, decreta que dicho fondo será administrado por la Conadi con el objeto de: a) otorgar subsidios para la adquisición de tierras por personas y comunidades indígenas cuando la superficie de que dispongan sea insuficiente; b) financiar mecanismos que permitan la solución de problemas de tierras, en especial con motivo del cumplimiento de resoluciones o transacciones judiciales o extrajudiciales que recaigan sobre tierras indígenas; y c) financiar la constitución, regularización o compra de derechos de agua o financiar obras destinadas a obtener este recurso (artículo 20).

Son múltiples los problemas de que adolece la política pública de tierras impulsada por Conadi. Tratándose de una política que ha operado por la vía de la compra de tierras, su efectividad ha dependido en gran medida de los recursos que el Estado ha destinado a su implementación. Si bien ha habido un gran incremento de recursos asignados para la compra de tierras entre el año 1994 y el 2017, la política de tierras no ha logado satisfacer la demanda por territorios y los recursos, a pesar de su alto monto, resultan escasos debido al espiral especulativo que ha generado la aplicación del Fondo de Tierras y Aguas Indígenas en el mercado de tierras en las regiones donde está operando, particularmente en el área correspondiente al territorio mapuche (Aylwin et al., 2014: 276). Cabe consignar que entre el año 1994 y el 2009 el precio promedio por hectárea pagado por Conadi con cargo al Fondo de Tierras y Aguas indígenas subió de $\$ 428.335$ hasta $\$ 3.539 .592$, lo que implica un incremento de 826\% (Donoso, 2017:321).

No obstante las deficiencias de estos mecanismos restitutorios, de acuerdo a la encuesta realizada por el Centro de Estudios Públicos (CEP) 2016, el 49\% de los mapuche estima que la deuda histórica con este pueblo se saldaría precisamente restituyéndoles tierras (Donoso, 2017:327). 
En el año 1994, el presupuesto asignado al Fondo de Tierras y Aguas Indígenas fue de 2.108.000 (miles de \$), mientras que en el año 2017 alcanzó a 80.819.749 (miles de \$). El total invertido desde la entrada en vigencia de la Ley Indígena hasta la fecha es 654.616.049 (miles de \$) (Donoso, 2017: 310).

El gasto público en la política de tierras indígenas ha tenido su mayor inversión en los cuatro años del segundo gobierno de Michelle Bachelet, con una inversión de \$287.178.334 (Donoso, 2017: 310).

Lo que ha descendido abruptamente es la entrega de tierras fiscales en dominio durante el gobierno de la Presidenta Michelle Bachelet. El pueblo mapuche recibió en dominio 2.311,81 hectáreas. Las tierras restituidas al pueblo mapuche se concentran en la región de Los Lagos. Sin embargo, en la región de La Araucanía, durante el segundo gobierno de Bachelet, las comunidades mapuche recibieron en dominio dos propiedades fiscales de una superficie total de 1,21 hectáreas. (Ministerio de Bienes Nacionales, octubre 2017) ${ }^{8}$.

No obstante estos esfuerzos, los conflictos por la tierra continúan. Lo que no está claro es la superficie de tierras reivindicadas, pues la demanda no está cuantificada. Los antecedentes que permiten dimensionar la demanda histórica no son suficientes y se requiere una instancia específica cuyo objetivo sea determinar la demanda de tierras y frente a la que las organizaciones representativas de los pueblos indígenas puedan delimitar su demanda territorial considerando los antecedentes históricos que la sustentan y la autodeterminación ${ }^{9}$. Además, se requiere de un mecanismo de adquisición de tierras menos vulnerable a la especulación que genera la compra de tierras, por lo que debería implementarse el mecanismo de la expropiación (CVHNT; 2008: 577; Núñez, 2017).

8. Información proporcionada por el Ministerio de Bienes Nacionales a la autora en el marco del Acuerdo de Solución Amistosa, Comisión Interamericana de Derechos Humanos, caso 12.904, Comunidad Chusmiza - Usmagama con Estado de Chile, Montevideo, octubre de 2017.

9. La Comisión de Verdad Histórica y Nuevo Trato (CVHNT) recomendó generar para estos efectos una Corporación de Reparación. Como fundamento a esta propuesta sostuvo, citamos textual: "La Comisión ha alcanzado la convicción que entregar los reclamos de tierras de los pueblos y comunidades indígenas al tiempo -esperando que el olvido las sepulte- constituiría un error que alentaría conflictos frecuentes y permanentes. Es deber del Estado -en opinión de la Comisión- instituir mecanismos a través de los cuales esas demandas puedan ser evaluadas y, cuando hubiere mérito para ello, satisfechas. La Comisión posee la convicción que instituir órganos y procedimientos para procesar y evaluar esas demandas y, cuando hubiere mérito, resolverlas, es el único camino que asegurará la plena integración de esos pueblos. Una reparación mediante mecanismos imparciales, que permitan juzgar esas demandas con sentido histórico, y financiada con cargo a rentas generales, es un mecanismo que la Comisión estima satisface criterios generales de justicia” (CVHNT, 2008: 576). 
Para dimensionar la demanda de tierras mapuche es necesario considerar una serie de antecedentes históricos. Las tierras reconocidas por el Estado de Chile a los mapuche durante el proceso de radicación que tuvo lugar entre los años 1884-1929 en lo que hoy se conoce como la región de La Araucanía (provincias de Malleco y Cautín), con posterioridad a la ocupación militar del territorio mapuche por parte del Ejército chileno bajo la dirección del general Cornelio Saavedra, alcanzaron las 407.696,06 hectáreas, lo que representa el 12,8\% de la superficie regional, mientras que el $87,2 \%$ restante fue destinado a la constitución de propiedad particular y fiscal (Correa et al., 2005:52). Los mapuche fueron reducidos en su propio territorio y se les otorgaron 2.318 títulos de merced para un total de 71.253 personas, con un promedio de 8,56 hectáreas por familia en Malleco y 5,29 hectáreas en Cautín (Correa et al., 2017: 50 y 52). Mientras, los particulares se adjudicaron en remate 1.125.120 hectáreas, lo que representa el 35,32\%, y en concesiones de colonización, 203.063 hectáreas, 6,37\%. Estas cifras corresponden al territorio mapuche en La Araucanía (Correa et al., 2005:52).

Durante el proceso de Reforma Agraria en las provincias de Malleco y Cautín se generaron las condiciones políticas para restituir a los mapuche una parte de las tierras que les fueron confiscadas durante la ocupación militar de su territorio y el proceso de radicación posterior. En este proceso fueron expropiados a favor de los mapuche 163 predios por un total de 152.416,88 hectáreas (Correa et al., 2005:298). El golpe de Estado frustró la recuperación de las tierras e implicó una brutal represión contra los mapuche. En efecto, revirtió los avances en el proceso de restitución de tierras y dio lugar a la contrarreforma agraria. Esta acción fue implementada por el Comité Ejecutivo Agrario, entidad que procedió a revocar los acuerdos expropiatorios y a restituir las tierras a sus antiguos propietarios. El 65\% de las tierras fue devuelto a sus titulares anteriores no indígenas, esto es, 97 predios del total de 163 con una superficie de 98.817,3 hectáreas (Correa et al., 2003:299). El resto, correspondiente a 63 predios, fue parcelado y entregado principalmente a los asentados no indígenas; menos del 50\% de los beneficiarios indígenas recibieron tierras (Correa et al., 2005:299).

"En síntesis, la superficie aproximada de tierras que tras la Contra Reforma Agraria llegó a poder de mapuches no supera las 25 mil hectáreas, esto es el 16\% de las tierras recuperadas entre 1962 y 1973 . El resto de las tierras, es decir, el 84\% fue devuelto a sus antiguos propietarios o se entregó en parcela a ex inquilinos o medieros" (Correa et al., 2005:299).

Al 2014, tras 20 años de implementación de la política de tierras impulsada por el Estado de Chile en el marco de la ley 19.253, se habían transferido 465 
mil hectáreas ${ }^{10}$, incluyendo compra de tierras particulares (187.173 hectáreas) y transferencia de predios fiscales (278.000 hectáreas).

\section{Grafico $\mathbf{N}^{\circ} 1^{11}$}

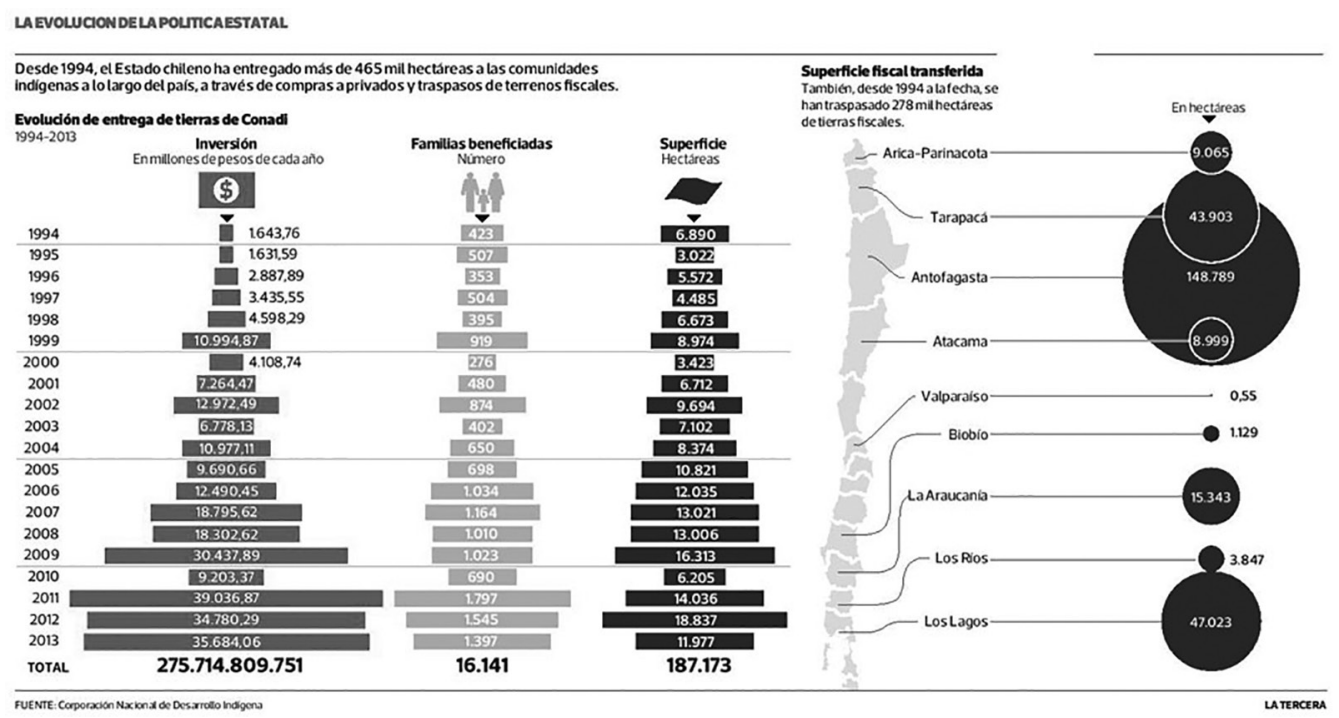

Fuente: diario La Tercera

No tenemos información actualizada de las tierras transferidas en el territorio mapuche ${ }^{12}$. Sin embargo, se sostiene en artículos de opinión ${ }^{13}$ y algunos investigadores también lo constatan (Núñez, 2017), que la cifra de tierras transferidas es muy parecida al total transferido durante el proceso de Reforma Agraria. Sin embargo, es claro que la demanda de tierras no se restringe a aquellas restituidas durante ese periodo y nuevamente confiscadas en la contrarreforma agraria. La demanda de tierras debe ser atendida considerando que se funda en una deuda histórica generada a partir de la usurpación del territorio indígena (ocupación militar y reducción,

10. [en línea] http://www.latercera.com/noticia/los-20-anos-de-traspasos-de-tierras-a-pueblosindigenas/ Consultada el 27 de enero de 2018.

11. [en línea] http://www.latercera.com/noticia/los-20-anos-de-traspasos-de-tierras-a-pueblosindigenas/ Consultada el 27 de enero de 2018.

12. La información de que disponemos corresponde al período 1994 - 2009 e indica que en la región de La Araucanía se transfirieron 53.305,56 hectáreas, beneficiando a 4917 familias (Conadi, 2009).

13. [en línea] http://www.economiaynegocios.cl/noticias/noticias.asp?id=95956 Consultada el 27 de enero de 2018. 
1863 - 1930) y con la perspectiva de reconstituir el territorio étnico como base fundamental para el ejercicio de la autodeterminación. Además, deben generarse mecanismos adecuados para satisfacer esta demanda.

\section{REPRESIÓN Y CRIMINALIZACIÓN DEL MOVIMIENTO MAPUCHE}

Hemos analizado en los párrafos precedentes la marginación social y económica del pueblo mapuche y sus miembros en Chile (Casen, 2015) y la ineficacia de las políticas públicas en materia de tierras (1994 - 2017). A ello se suma una constante dinámica de represión y criminalización que contemporáneamente han vivido los mapuche como respuesta del Estado a las acciones indígenas destinadas a visibilizar sus demandas territoriales, defender sus territorios y ejercer sus derechos.

Para dar cuenta de la represión y criminalización que sufren los mapuche defensores y defensoras de sus derechos territoriales revisaremos sucintamente tres hitos históricos de data relativamente reciente: el proceso de Reforma Agraria, la contrarreforma agraria y la situación actual.

La acción represiva del Estado de Chile en la época de la Reforma Agraria se dirigió selectivamente contra las comunidades indígenas que reivindicaron sus derechos históricos al territorio durante dicho proceso. En el caso mapuche estas violaciones son particularmente graves, pues visibilizan que la violencia del Estado contra el pueblo mapuche y sus miembros es una constante histórica, que tiene como base la "usurpación" del territorio mapuche y la validación de estos actos por el Estado. Además, se debe tener en cuenta que estas violaciones no tienen sólo una dimensión individual, sino que también colectiva.

Recogemos algunos de los numerosos testimonios que dan cuenta de la represión que se vivió en las provincias de Malleco y Cautín durante la dictadura militar (1973 - 1989) y que dan cuenta de la persecución política; las formas de represión y la responsabilidad de los agentes estatales; y la usurpación de tierras y otros bienes comunitarios como consecuencia de la contrarreforma agraria.

\section{i. Persecución política}

José Ernesto Millalen, encargado de ganadería del asentamiento Chile Fértil, Galvarino:

"A mí me dieron muchísimo, por ser dirigente sufrí todas las torturas. A mí me quemaron, me sentaban en una estufa eléctrica, me quemaban con puchos de cigarros, y así tantas cosas. Preguntaban quién era comunista, te acusaban de ser comunista, preguntaban por Teillier, que en ese tiempo era Gobernador 
de Lautaro. A mí me tomaron porque pensaban que era comunista, o porque llegué al Asentamiento, no sé, porque que era dirigente... me empelotaron y me sentaron ahí y me dijeron "tú sós comunista"... (Correa et al., 2005: 286).

\section{ii. Los torturadores, las prácticas de tortura y la responsabilidad de Pinochet}

Pedro Rain Varela, dirigente de la Cooperativa Regional Lautaro de Lumaco:

"Yo estuve en la cárcel en el 73. Fui detenido el 14 de Septiembre, me fueron a buscar a la casa los militares y me tuvieron 18 días en la tortura en Traiguén, en la Fiscalía de Traiguén. Yo sabía que eso venía, porque yo tenía una radio a pilas chiquitita y escuchaba las noticias y escuché cuando habló Pinochet diciendo "el que ponga resistencia bala con él" y hoy día Pinochet niega que dio orden, y la dio públicamente... En mi caso mire cómo me dejaron el cuello y bajo la nuca con la tortura, me colocaron corriente, y me sumieron en un tambor no sé con qué líquido. Y la paliza era siempre a la una de la mañana, nos tiraban al agua y luego decían hasta allí no más, el que se pasaba bala con él. A mí me intentaron matar pero no pudieron. Los militares me llevaron por un camino a una quebrada que queda entre Traiguén y Galvarino, y me tiran desde un cerro empinado al fondo de una quebrada donde había un río, y caí de vuelta y vuelta en pelota sin ropa, como a la una de la madrugada y esto lo hacían a la hora que no habían movilización y donde nadie escuchara. Me tiraron quebrada abajo, no estaría permitido a Dios que mi vida se fuera al otro lado, y tuve la suerte que había un islita donde había arena, solo el hombro me anduvo molestando un poco. Ahí me tenían y ellos arriba del cerro, cuatro militares me tiraban para abajo y la helada que había a esa hora, todo blanquito, y yo abajo, bueno y porque no les hablo a estos burros para arriba, y les digo si me quieren matar porque no me matan. De arriba dijeron "está vivo es huevón" y comenzaron a secretearse, "para que lo vamos a matar", y mandaron a los milicos a buscarme, bajaron como pudieron y me llevaron para arriba y me hicieron una cama de pura piedra y me tenían tirado. Les volvía a decir porque no me matan, para que me hacen sufrir tanto, que más que gasten un tiro o dos tiros, la vida ya no la siento, no es nada. "Usted cree que somos asesinos", me dijo el teniente, le dije "no creo que sean asesinos pero tampoco es bueno lo que están haciendo conmigo". Me preguntaron si tenía señora e hijos, les contesté que sí y un sobrino y una sobrina. "Ya pásale la ropa y me subieron a la Toyota otra vez. Me preguntaba dónde me llevaran esta vez, me trajeron y mentalmente yo no lo perdí, no como otras personas que al ver tantas barbaridades sicológicamente perdían la mente, me daban ganas de llorar y aguantaba, y cuando íbamos llegando a Traiguén, 
miro para adelante y digo, ya no me mataron ná... Llegaron y me entregaron en el Regimiento al Capitán Eduardo Bravo que era el que torturaba (...) otros torturadores, todavía están aquí en Traiguén, Aguilera y un mapuche - si hay mapuches que perteneciendo a un Servicio de las Fuerzas Armadas se ponen más brutos que los otros brutos - un tal Luis Pailahueque, sargento jubilado, y Eduardo Aqueveque, sargento del Regimiento Miraflores de Traiguén..." (Correa et al., 2005: 289).

\section{iii. La contrarreforma: nueva usurpación de tierras y bienes comunitarios de producción}

Felix Huentelaf Alañaco, de la comunidad mapuche de San Ramón, fundo Chesque.

"Llega el Golpe Militar y nos echan para afuera, nos quitan todo, al patrón le entregan la tierra aunque ya el Estado la había pagado, toman los animales y todo eso, y nosotros, que éramos de la comunidad "ándate, otro que venga para acá". Ahí fui tomado, porque era dirigente del Asentamiento Michimalonko, después del Golpe me tuvieron preso en Loncoche, de allá me sacaron, me trajeron a la $\mathrm{FACH}$, me torturaron, 5 días vendado, y aquí está el hombre, el mapuche, reconozco mi sangre y estoy orgulloso, porque el mapuche es un hombre de lucha, es un hombre duro, contra más le pega más ensoberbia la sangre porque sabe y tiene conciencia porqué está luchando.

Fui torturado, estuve en la cárcel de Temuco, muchos me conocieron ahí, fui trasladado a Lautaro para cumplir mi pena y estuve más de tres años preso. Salí y vivo en mi comunidad, herencia de mis padres, con un hermano y ahí seguimos en la organización, siempre organizados" (Correa et al., 2005: 291).

Pero la situación del pueblo mapuche y sus miembros no ha variado respecto a ese periodo de la historia de Chile. En la actualidad siguen luchando por recuperar las tierras usurpadas, las mismas que reivindicaron en los Juzgados de Indios (1930 - 1961) y, posteriormente, en el marco de la Reforma Agraria. Sus acciones para la recuperación de esas tierras siguen siendo criminalizadas y los mapuches continúan siendo encarcelados, torturados y asesinados.

Según investigaciones realizadas por Myrna Villegas, entre 2001 y 2016 se iniciaron 21 procesos contra personas mapuche por Ley Antiterrorista y se condenó a nueve personas $^{14}$, de las cuales ocho recurrieron al Sistema Interamericano de Derechos

14. [en línea] http://www.derecho.uchile.cl/comunicaciones/columnas-de-opinion/137354/derechoshumanos-ley-antiterrorista-y-mapuchebrmyrna-villegas Consultada el 27 de enero de 2018. 
Humanos. La Corte Interamericana de Derechos Humanos, en sentencia de 29 de mayo de $2013^{15}$, condenó al Estado chileno por violar derechos fundamentales garantizados en la Convención Americana a ocho miembros del pueblo mapuche condenados por Ley Antiterrorista, caso Norin Catriman y otros vs. la República de Chile.

En la sentencia, la Corte concluyó que el Estado de Chile violó el principio de legalidad y el derecho a la presunción de inocencia en perjuicio de las ocho víctimas de este caso, por haber mantenido vigente y aplicado el artículo $1^{\circ}$ de la ley $\mathrm{N}^{\circ}$ 18.314, que contenía una presunción legal del elemento subjetivo del tipo terrorista.

La Corte también encontró que en la fundamentación de las sentencias condenatorias se utilizaron razonamientos que denotaban estereotipos y prejuicios, lo cual configuró una violación del principio de igualdad y no discriminación y el derecho a la igual protección de la ley.

El fallo hace un llamado de atención por la existencia de una legislación que no garantiza el derecho al debido proceso, poniendo especial atención y haciendo recomendaciones en relación al uso de testigos con identidad reservada que no garantizan el derecho a la contra - interrogación, y ordena que se modifique esta legislación.

En síntesis, la Corte señaló que el Estado violó el principio de legalidad y de presunción de inocencia, el principio de igualdad ante la ley y garantías judiciales. Además de vulnerar el derecho a la defensa, a la libertad personal, libertad de pensamiento y expresión, el derecho a recurrir un fallo ante un tribunal superior y, por último, de violar los derechos políticos ${ }^{16}$.

Respecto a la definición de terrorismo, se establece que no se han seguido las directrices internacionales (Resolución 1566/2004) y Convenciones Internacionales ${ }^{17}$.

La Corte constata que varios órganos y expertos internacionales han afirmado que Chile no ha resuelto de forma efectiva las causas que dan lugar a la protesta social mapuche.

Este es el caso de Ben Emmerson, relator especial sobre la promoción y protección de derechos humanos en la lucha contra el terrorismo, quien en su

15. [en línea] http://www.corteidh.or.cr/docs/casos/articulos/seriec_279_esp.pdf. Consultada el 28 de enero de 2018.

16. [en línea] http://www.corteidh.or.cr/docs/casos/articulos/seriec_279_esp.pdf Consultada el 27 de enero de 2018.

17. [R] esolución 1566 (2004)". Cfr. UN Doc. A/HRC/16/51, 21 de diciembre de 2010, Consejo de Derechos Humanos, Informe del Relator Especial sobre la promoción y protección de los derechos humanos y las libertades fundamentales en la lucha contra el terrorismo, Sr. Martin Scheinin, Diez esferas de mejores prácticas en la lucha contra el terrorismo, párrs. 23, 27 y 28. 
visita a Chile en julio de 2013 sostuvo: "[q]ue cuando el Estado no cumple con las expectativas de solucionar las reivindicaciones territoriales indígenas mapuche permanece latente el riesgo de que las protestas sociales escalen de nivel. En este sentido, resulta prioritario que el Estado garantice una atención y solución adecuada y efectiva a tales reclamaciones para proteger y garantizar tanto los derechos del pueblo indígena como los del resto de los miembros de la sociedad en dichas regiones" $"$.

En la misma línea se ha pronunciado el Comité de Derechos Humanos ONU (Observaciones finales sobre el sexto informe periódico de Chile, 13 de agosto de 2014 (CCPR/C/CHL/CO/6), párr. 7), mencionado en la sentencia de la Corte, que establece:

El Estado parte debe reformar la Ley Antiterrorista y adoptar una definición clara y precisa de los delitos de terrorismo para asegurar que las actividades que realizan los agentes del orden en el marco de la lucha contra el terrorismo no estén dirigidas a determinadas personas por su origen étnico o cualquier motivo social o cultural.

Asimismo, debe asegurar que las garantías procesales, contenidas en el artículo 14 del Pacto, sean respetadas. El Comité insta al Estado parte a abstenerse de aplicar la Ley Antiterrorista en contra de los mapuche.

Lo propio ha señalado el Comité para la Eliminación de la Discriminación Racial ONU (Observaciones finales sobre los informes periódicos $19^{\circ}$ a $21^{\circ}$ de Chile, 30 de agosto de 2013, CERD/C/CHL/CO/19-21), párr. 14), que plantea que b) asegure que la Ley Antiterrorista no sea aplicada a miembros de la comunidad mapuche por actos de demanda social.

Desde el año 2001 a la fecha se registran ocho asesinatos de personas mapuche directamente vinculadas con los conflictos generados en el marco de la reivindicación territorial mapuche:

1. Edmundo Alex Lemunao Saavedra (2002)

Niño de 17 años asesinado durante la ocupación del fundo Santa Elisa, propiedad de la Forestal Mininco. El autor del hecho fue el teniente de Carabineros Marco Aurelio Treuer, quien utilizó una escopeta Winchester calibre 1.

18. [en línea] http://acnudh.org/informe-del-relator-especial-sobre-la-promocion-y-proteccionde-los-derechos-humanos-y-las-libertades-fundamentales-en-la-lucha-contra-el-terrorismo/. Consultado el 28 de enero de 2018. 


\section{Zenén Alfonso Díaz Nécul (2005)}

Niño de 17 años que murió atropellado por un camión forestal durante un corte de la ruta 5 sur. Hasta ahora nadie ha sido procesado por el hecho.

3. Lonko Juan Lorenzo Collihuin Catril (2006)

Adulto mayor de 71 años asesinado durante un allanamiento ocurrido en el año 2006 en el sector de Bollilco Grande, Nueva Imperial. El autor de este hecho es el sargento de Carabineros Luis Mariman.

4. Matías Valentín Catrileo Quezada (2008)

Joven de 23 años asesinado en el fundo Santa Margarita, de la comuna de Vilcún, que está a nombre de Jorge Luchsinger y es reclamado por la comunidad Lleupeco Vilcún. El autor de los hechos es el cabo de Carabineros Walter Ramírez. Catrileo fue asesinado por la espalda con una subametralladora UZI.

5. Jaime Facundo Mendoza Collio (2009)

Joven de 24 años asesinado durante la ocupación del fundo San Sebastián, reivindicado por su comunidad. El autor de los disparos es el cabo Patricio Jara Muñoz.

\section{Rodrigo Melinao Lican (2013)}

Joven de 26 años miembro de la comunidad Raen Mapu del sector de Lolokos. Fue encontrado muerto en la madrugada del 6 de agosto del 2013 al interior de la parcela $\mathrm{N}^{\circ} 4$ del sector Chiguaihue, en Pidima. Fue asesinado con un disparo de escopeta a corta distancia en el tórax.

7. José Mauricio Quintriqueo Huaiquimil (2014)

Adulto de 32 años. Murió la mañana del 1 de octubre del 2014 tras ser intencionalmente atropellado con un tractor por un inquilino del fundo Nilpe, en la comuna de Galvarino.

8. Víctor Manuel Mendoza Collio (2014)

Werkén de su lof Manuel Pillan y primo de Jaime Mendoza Collio. Falleció el 29 de octubre del 2014 después de que dos desconocidos llegaron a su casa, en el sector de Pidima, Ercilla, y le dispararon un tiro al tórax en presencia de su hija de seis años de edad.

Fuente: elaboración propia a partir de información periodística ${ }^{19}$.

19. [en línea] https://www.laizquierdadiario.cl/14-mapuches-asesinados-en-los-gobiernos-de-laConcertacion-y-la-derecha Consultada el 27 de enero de 2018. 
El Estado no claudica en su estrategia de criminalización, lo que inviabiliza una convivencia democrática con el pueblo mapuche. Los procesos por Ley Antiterrorista continúan ${ }^{20}$, los crímenes contra mapuche quedan impunes o las sanciones a los responsables son irrisorias ${ }^{21} \mathrm{y}$, recientemente, hemos sido testigos de estrategias de montaje efectuadas por agentes del Estado para incriminar a líderes mapuche y de este modo neutralizar sus acciones políticas ${ }^{22}$.

\section{CONCLUSIONES}

El pueblo mapuche y sus miembros viven en condiciones de marginalidad social, económica y política. Constituyen el grupo más vulnerable de la población y así lo demuestran los indicadores de bienestar socio-económico, que los posiciona como los más pobres del país, con los peores niveles de acceso a servicios básicos, educación, salud y vivienda, y discriminados en el ámbito laboral, en particular respecto a sus niveles de ingreso en relación a los otros sectores de la población.

No existe una política de reconocimiento efectivo de los derechos colectivos a la tierra, y este, que es el conflicto histórico más candente entre el Estado y los mapuche, se perpetúa. Parece insoslayable adoptar políticas que permitan generar, como se recomienda en este artículo, una instancia que cuantifique la demanda de tierras mapuche y genere mecanismos efectivos de restitución por medio de la expropiación. Que, además, compatibilice esta política con una que inste a reconstituir los territorios ancestrales, establecer modelos autónomos de gobernanza y que permita el efectivo ejercicio del derecho a la libre determinación.

Finalmente, el Estado debe buscar salidas políticas al conflicto histórico con el pueblo mapuche y abdicar de estrategias represivas y de criminalización que agudizan el conflicto y vulneran principios democráticos esenciales como son los derechos fundamentales reconocidos en la Constitución y en los instrumentos internacionales de derechos humanos ratificados y vigentes en Chile.

20. [en línea] https://observatorio.cl/la-ley-antiterrorista-y-el-juicio-luchsinger-mackay-una-vezmas-chile-incumpliendo-sus-obligaciones-internacionales/ Consultada el 27 de enero de 2018.

21. [en línea] http://radio.uchile.cl/2011/11/07/familiares-mapuche-denuncian-impunidad-encrimenes-de-alex-lemun-y-matias-catrileo/ Consultada el 27 de enero de 2018.

22. [en línea] http://www.t13.cl/noticia/nacional/de-aparatosa-detencion-montaje-hitosoperacion-huracan. Consultada el 27 de enero de 2018. 


\section{REFERENCIAS}

ANAYA, James. 2005. Los pueblos indígenas en el derecho internacional. Editorial Trotta. Universidad Internacional de Andalucía. Madrid. 493 p.

AYLWIN José, Matías MEZA-LOPEHANDIA y Nancy YÁÑEZ. 2014. Los pueblos indigenas y el derecho, Lom, Santiago. 604 p.

COMISIÓN ECONÓMICA PARA AMÉRICA LATINA Y EL CARIBE (CEPAL). Los pueblos indígenas en América Latina, avances en el último decenio y retos pendientes para la garantía de sus derechos, Santiago de Chile, 2014. Disponible en: http://repositorio.cepal.org/bitstream/ handle/11362/37222/S1420521_es.pdf

COMISION DE VERDAD HISTÓRICA Y NUEVO TRATO. 2008. Informe de la Comisión de Verdad Histórica y Nuevo Trato con los Pueblos Indígenas. Primera Edición. Comisionado Presidencial para Asuntos Indígenas, Santiago. [en línea] http://www.memoriachilena.cl/602/articles-122901_recurso_2. pdf. Consultado el 28 de Enero de 2018.

CORREA, Martín, Raúl MOLINA y Nancy YÁÑEZ. 2005. La Reforma Agraria y las tierras mapuche, Lom, Santiago. 470 p.

DONOSO, Sebastián. 2017. Compra de predios en conflicto. Análisis crítico y una propuesta. En: Aninat, Isabel, Verónica Figueroa y Ricardo González (Eds.). "El pueblo mapuche en el siglo XXI. Propuestas para un nuevo entendimiento entre culturas en Chile”. Centro de Estudios Públicos, Santiago. Pp. 293 - 342.

MARIMAN, José. 2012. Autodeterminación. Ideas politicas mapuche en el albor del siglo XXI, Lom, Santiago, 357 p.

NÚÑEZ POBLETE, Manuel A. La constitución de la propiedad indígena como fin de la expropiación por interés nacional. Rev. Derecho (Valdivia) [online]. 2017, vol.30, n.1 [citado 2018-01-28], pp.205-233. Disponible en: $\quad<$ https://scielo.conicyt.cl/scielo.php?script=sci_arttext\&pid=S071809502017000100009\&lng=es\&nrm=iso >. ISSN 0718-0950. http://dx.doi. org/10.4067/S0718-09502017000100009.

VILLEGAS, Myrna.s/f.Derechos bumanos, Ley Antiterroristay mapuche. [en línea] http:/ / www.derecho.uchile.cl/comunicaciones/columnas-de-opinion/137354/ derechos-humanos-ley-antiterrorista-y-mapuchebrmyrna-villegas Consultada el 27 de enero de 2018. 